\title{
An exploratory study of work-life balance in Nigeria: Employees' perspectives of coping with the role conflicts
}

\author{
Akanji, Babatunde $\square$ \\ University of Wales, United Kingdom (toyinbabs01@yahoo.com)
}

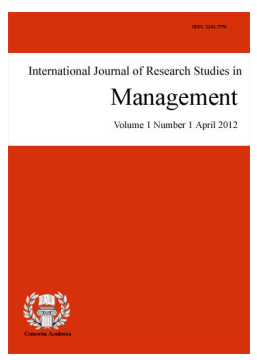

Accepted: 11 October 2013

ISSN: $2243-7770$ Online ISSN: 2243-7789

OPEN ACCESS

\section{Abstract}

Using a phenomenological methodology, the purpose of this study is to examine the prevalence of work-life conflicts (WLC) in Nigeria. Evidently, work-life research is a social concept originating from the western societies but over the years, advanced management and business studies are beginning to emerge showcasing the relevance, significance and challenges of Work-Life Balance (WLB) practices in developing nations. Against this backdrop, 51 in-depth interviews were conducted with employees working in the Nigerian service industry (i.e. banks, call center, hotel services and insurance firms) about their cultural perceptions and knowledge of work-life balance. Study findings manifested views alleging the prominence of role conflict situations rather than desired expectations of available social incentives for appropriate management of employees' work and family affairs. This were attributed to the adverse macro environmental conditions entrenched in so many social-economic upheavals found to be plaguing Nigeria as a whole. Thus, the antecedents of these national issues have necessitated personal coping strategies utilized by participants of current study as moderating buffers against role imbalances encountered. Thus, this paper provides a preliminary study that provides an academic platform for further research into circumstances instigating role conflicts in African societies by presenting major impediments detected to hinder workable WLB practices in Nigeria.

Keywords: work-life balance; work-life conflict; role conflicts; Nigeria; African societies 


\section{An exploratory study of work-life balance in Nigeria: Employees' perspectives of coping with the role conflicts}

\section{Introduction}

Across various national contexts, Work-Life Balance (WLB) is becoming a topical issue of discourse at government, organizational, policy making and academic levels (Eikhof, Warhurst, \& Haunschild, 2007). It is common theme in such discourses that employees' are required to consolidate their efforts in finding the right balance between their work and non-work roles while organizations are been investigated on how and why they should implement a variety of WLB practices and policies to foster workplace well-being without compromising business objectives of performance, productivity and profits (Gregory \& Milner, 2009). Thus, in our modern day labor markets, the significance of WLB especially in employee relations tends to critically explore prospects that impacts positively on maintaining employer-employee relationships that contribute to employee's commitment, motivation, job satisfaction, flexibility and acceptable workplace morale (Greenhaus \& Powell, 2006). However, the conflict situations encountered by working adults in managing their routine obligations between paid work and private life domains still dominates most work-life studies with a plethora of literature stressing the realities of role conflicts and negative outcomes that presents challenges exacerbating WLB agendas (Demerouti, Tarris, \& Bakker, 2007).

Though over the years, there has been a high level of concentration of work-life research in western economies but scholarly studies are beginning to spread to non-western context because of the ubiquitous nature of this topical issues gaining recognition globally (Baral \& Bhargava, 2010) and this is the main reason necessitating the development of this paper. The popular perception of WLB in western countries have often been how WLB incentives such as compressed hours, flexible arrangements, paid maternity leave, re-entry schemes, paternity leave, part-time work, home commuting and so on are created and implemented by organizations to help employees find a reasonable integration between their employments and non-work aspects of their lives (Crompton \& Lyonette, 2006). While a balanced framework is the ideal setting for well-being and work productivity, it is documented that work-life conflict is still prevalent in the western regions because of circumstances such as their changing demographics, long working hours culture, job insecurity due to the global recessions that is making organizations adopt minimal standards for work-life practices and policies (Bond, 2004; Sanse'au \& Smith 2012).

The Nigerian society which is the context of this study is also faced with national challenges that are most often focused on issues of leadership failures. Thus, there are a swathe of literature mostly published by Nigerian authors that highlights the socio-economic problems embedded in our political culture which mainly concentrates on poor leadership and management failures which has been the cause of high unemployment rates, poverty, poor infrastructural developments, low standard of living and corruption practices (Okpara, 2006; Okpara \& Wynn 2007; Okogbule, 2007; Ampratwum, 2008). This raises curiosity on how the adult Nigeria worker in their quest to make a rational livelihood, manages pressures between their working and family life given the array of national challenges that the Nigerian society presents. How Nigerians develop the ability to cope desirably and maintain effective functioning at work and home (Clark, 2000) is the line of enquiry of present study. Thus, the objective of this paper runs parallel with its research question which is to present a scholarly portrait of the social content of WLB practices as perceived by Nigerian service workers. This study further investigates coping conditions that are employed by participants to moderate conflict situations they encounter on a daily basis in their work-life interface. Our study will also examine gender perceptions of WLB in Nigeria with regards any stereotypes and discriminatory attitudes experienced by working women impeding their satisfactorily participation on their job and family affairs.

Nigeria is documented as one of the most populous countries in Africa (Okpara, 2006) with an increasing 
population of about 146 million and a diverse nation with over 250 ethnic groupings (CIA World Factbook, 2010). Nigerians officially speak English language but the country is a multi-lingual state with over 503 indigenous languages. Nigeria's religious affiliation stands at 50\% Muslim devotees, $40 \%$ Christians and $10 \%$ of the entire population engage in customary beliefs. The work force is estimated at 47.48 million and labour force by occupation documented at $70 \%$ in agriculture, $10 \%$ in industry and $20 \%$ services (CIA World Factbook, 2010). Unfortunately, Nigeria's unemployment rate is high and stands at $4.9 \%$ with a majority of her citizens under poverty line standing at $70 \%$ as at 2007 (CIA World Factbook, 2010). This makes standard of living in Nigeria one of the poorest in the world with a GDP of $9.5 \%$ as at 2010 (CIA World Factbook, 2010). Work structures in Nigeria are broadly divided into two categories. First, is formal occupation which could either be in the public sector comprising of government owned institutions like public hospitals, government funded universities, police force and so on or private organizations owned by wealthy Nigerians or foreign investors like the telecommunications sector, hostel businesses, transport and private universities. Second, is the informal economic sector with entrepreneur indigenes engaging in self-employed businesses mostly on small medium scale (Okpara, 2006). The terms and conditions of employment with exception to wages for both public and private organisations are regulated by the Nigerian Employment Act of 1971 which has minimal provisions for family responsive policies (Epie, 2009). With this brief narrative of the Nigerian context in mind, the next section of this paper covers a review of literature on work-life balance followed by the methodology used in current research. Thereafter, data analysis and conclusions are drawn from study while the limitations of study are also highlighted.

\section{Literature Review}

Work-life balance within literature often presents a significant social ideology which is based on the fact that living a fulfilled and satisfactory adult life requires that the economic and social life of an individual should be classified as less competing priorities but rather complementary elements of a full life (Manfredi \& Holliday, 2004). Felstead, Gallie, and Green (2002) further suggested that the social meaning of WLB assumes an integrated connection between "institutional and cultural times and spaces of work and non-work matters in societies where income is mainly created and distributed through labor markets". Originally, Work-Life Balance matters developed as an exclusive high profile topical issue of discourse in most advanced economies such as U.S.A, Australia, United Kingdom and other European countries and it is common theme in such western discourse that employees are required to consolidate their efforts in finding the right balance between their work and non-work roles while organizations seeks to implement a variety of WLB practices and policies to foster performance and increase profit margins. Thus, researches in such advanced labor markets expresses the significance of WLB especially in employment relations that tend to critically explore prospects that impacts on maintaining employer-employee relationships that contribute to both individual and organizational outcomes such as productivity, motivation, job satisfaction, atypical work patterns and acceptable workplace morale. A variety of WLB solutions such flexitime, job sharing, part-time work, home-telecommuting, compressed hours, part-time, paid maternity, phased retirement and so on to foster workplace performance.

However, in reality, attaining this balanced status between work and domestic life still portrays a central challenge for employees across various occupational contexts (Greenhuas, Collins, \& Shaw, 2003; Valour, 2007). This is because there seems to be more literature emphasizing the dominance of work life conflict and role conflicts encountered by workers due to the changing nature of many working environments that is leading to increased stressful work characteristics causing more conflict situations (Greenhaus \& Beutell 1985) rather than the desired work-family integration advocated in theory and practice. The phrase 'work-family conflict' (WFC) used interchangeably with work-family conflict (WFC) emerged in the 1980s evidently because of influx of women participation in employment which was marked by a period of increased market liberalization and accompanied by a surge in academic research and public awareness on occupational stress and its associated negative outcomes (Lewis \& Cooper, 1999). The WFC is the form of inter-role struggle whereby there lies incompatibility between work and family responsibilities resulting into time or strain-based pressures (Roche \& 
Akanji, B.

Haar, 2010). Trends in work-life discourse has manifestly shown dominance of work-family conflict research with origins in numerous studies premised on theories that the two domains are in a state of perpetual conflict (Greenhaus \& Beutell, 1985).

The emphasis on incompatible of role demands was historically theorized in the scarcity hypothesis by Sieber in 1974. The empirical proposition of Sieber center of the fact that antecedents surrounding the availability of time, resource, and energy within each role are finite and limited to meet the increasingly high and insatiable demands generated from both roles (Sieber, 1974). In other words, the scarcity theory is indicative of the fact that there is a restrictive gauge on a person's physiological and psychological resources and as a result of this, competing demands encountered between work and domestic life degenerates into a tug-of-war experience where the involvement in one domain is usually at the expense of the other (Roche \& Haar, 2010). This most often times generates negative outcomes like occupational stress, burnout or health issues. However, there have been criticisms of the perpetual dominance on the conflict hypothesis in work-life research with limited emphasis on the role enrichment concept that forms the essence of the WLB rationale. It is observed that the conflict experiences may be a mere reactive proposition which is highly subjective and may be a personalized weakness of individuals who cannot enact and manage conflict roles circumspectly.

\subsection{Coping with Role Conflicts}

From the above, it is evident that employees' experiencing role conflicts often encounter high levels of stress from both domains of their life roles that requires various coping strategies to moderate the impact of stress induced outcomes encountered at work and home (Beutell \& Wittig-Berman 2008). The suggested coping strategies within literature could either be cognitive or behavioral or emotionally based which Lazarus \& Folkman (1984) presented as coping beliefs that are generated from various levels of physical and mental resources utilized after the appraisal levels of stress encounters are explicitly or implicitly achieved. Lazarus \& Folkman (1984) are popularly known for conceptualizing a transactional stress model that theorizes stress as imbalances experiences between levels of demands and low resource availability. In these circumstances, stress is adjudged as when pressures from work or private life situations exceed an individual's perceived physical and psychological resources to manage and reduce stressful circumstances (Lazarus \& Folkman 1984; Rotondo \& Kincaid 2008).

Although there are different types of coping methods suggested within literature as ways people manage stressful conditions ranging from problem-solving approaches, positive appraisal, assistance seeking and avoidance/surrender methods (Folkman \& Moskowitz, 2004). Brief discussions of these identified coping strategies are considered in turns. The problem-solving approach is a proactive method of coping which occurs when an individual consolidates personal efforts to remove conditions causing distress (negative stress). This may include asserting energies at gathering detailed information about the stressful situations, strategic planning and eventual decisions reached at eliminating or dealing directly with role conflicts after transactional appraisals (Lazarus \& Folkman 1984). It simply means increasing the supply of personal resources to deal with the situations causing the stressful occasion or disturbing environment.

With regards positive thinking strategies, it is theorized that coping are displayed in a mentally optimistic way in moderating the impact of stressful encounters. This approach is more emotionally inclined by showing psychological abilities to manage painful emotional reactions in a temperate form especially when conflict felt at work or family domains cannot be altered momentarily (Herman-Stahl, Stemmier, \& Petersen, 1995). For the assistance or self-seeking solutions, here people seek for some form of social support from others in managing potential role conflicts. This could be help from family members where the conflicts are mainly generated from incompatibility in managing family responsibilities or work support from colleagues, managers or superiors if the situation relates to work-based stress (Adams, King \& King, 1996; Rotondo \& Kincaid 2008). Finally, the avoidance/surrender coping methods are passive responses to stress-induced environments and circumstances by generating ill-feelings and sometimes irrational decisions taken to deal with adversarial accounts. This strategy is 
said to be mainly impulsive with the thinking that relying on self-resignation and state of helplessness is the best option under such circumstances (Rotondo, Carlson, \& Kincaid, 2003). Hypothetical examples in this regard are the resentful coping beliefs that people in situations of a marriage divorce due to lack of tolerance between couples. Another example is showing signs of voluntary withdrawal from employment as result of subjective feelings towards an employer. Therefore, utilizing this various coping methods within literature, we contextualize how Nigerian workers within the parameters of our study perceive and cope with imbalances encountered between their work and family roles.

\section{Methodology}

This qualitative research mainly relied on the perceptions of the participants of current study with a focus on entering interactions with employees in understanding their viewpoints with regards the subject matter under investigation (Saunders, Lewis, \& Thornhill, 2007). These types of studies are subjective in nature but important in retrieving specific information about certain behavioral patterns, observational beliefs and understanding of people's sentiments about their WLB realities. Thus, a judgmental sample of 51 workers engaged in the banking, call center work, hotel service staffs and car insurance business drawn across the Lagos state metropolis were chosen as subjects of study.

The study was carried out in the metropolitan Lagos state of Nigeria which is known for a bee halve of commercial activities. The occupational group chosen was Nigerian workers involved in customer service roles either by voice to voice or face to face contacts with customers in their daily work routines. This was intentionally done because richer data was obtained from this particular labor set of service workers due to the intensity of emotional labor involved in their job roles. Participants of present study were within the age brackets of 20-55 years old. Most of the interviews were conducted in the respective workplaces of most participants after permission was sought and granted from their employers while other interviewees preferred telephone conversations during their long hour break and some choose off-site interviews.

All the face to face and telephone interviews were conducted in English language and lasted for about an hour. The interview processes began with an introduction of the subject matter under consideration, confidentiality parameters explained so that none of the participants is under any illusion of their voluntary participation. Semi-structured interviews were conducted but questions asked were modified flexibly for purposes of retrieving as much rich data that answered all the lines of intended enquiry. Subsequently, analysis was carried out almost simultaneously because of the manageable number of participants.

\subsection{Design}

Epistemologically, the study drew primarily from the interpretivist-phenomenological paradigm for the purposes of identifying the real life situations of WLB challenges experienced amongst Nigerian service employees. Thus, the existing phenomenological research was designed to gather deep information and relevant views through inductive discussions with participants about how they relate, interpret and perceive WLB in the Nigerian context. The research method utilized was a case study approach. Robson (2002, p. 178) defined case study as "a strategy for doing research which involves an empirical investigation of a particular contemporary phenomenon within its real life context using multiple sources of evidence". The main aim of using a case study method was to gain an in-depth understanding of the concept of work-life balance in the cultural context of Nigeria and examine how the participants of study cope with perceived role conflicts in their service roles. Thus, validity of findings was achieved through extensive semi-structured interviews with participants about their perception of WLB in a context different from develop countries. At the end of all interviews with participants, our current study produced 75 pages of verbatim transcribed interview data while data analysis began with coding similar themes into theoretically derived categories.

Our analysis focused on three dominant categories which were discovered as major influences causing role 
Akanji, B.

conflicts in the lives of participants while various coping mechanisms were narrated as personal resources utilized to mediate WLC situations. Using the open coding systems, the derived meaning of the above categories was distilled from a few words, sentences or paragraphs from the transcribed data of study. For example, “...we are experiencing work-life conflict because of most leadership failures in our polity...”; ...on getting home from work, I am so tired because of time spent in traffic because of the bad roads in Nigeria which the authorities seems not care about..."; corruption is a major issue in our political life and various organizational settings...; All this various units of data were collapsed and subsequently labeled to form a main category of sources of WLC originating from national downturns earlier identified in the study.

Other units of data such as "...with all my stressful situations experienced at my workplace and family life...I am still coping..."; "...I am grateful my mother-in-law who supports me by looking after my children when I am off to work..." Also, these types of narrative were collapsed and labeled under the core category of coping methods employed by participants of study. Thus, the open coding employed in data analysis engaged in rigorous processes of breaking down, examining, comparing, conceptualizing and categorizing the entire data while discovery of emerging theories were made below.

\subsection{Data analysis and discussions}

One of the salient themes that continuously emerged from interviews with participants was Nigeria's social and economic challenges causing WLC. It was discovered that there was a prevailing misfit between the participants and their working environments (French, 1973) because of the failing culture of insensitivity to the work-life plights of the working class in the country. However, the participants explained that their role conflict situations was not solely originating from their workplace but a dynamic interactions caused by the culture in Nigeria that gives little recognition to work and life balance policies and practices in organizations. Furthermore, all the participants' interviewed in this study expressed deep concerns regarding trends in the political, economic and social challenges facing Nigeria as the primary sources of their work-life conflict. It was found that one major gap in most work-life balance literature is the concentration of research at the Micro (individual) and Macro (organizational) levels while little research is carried out to find out the impact of the Meso (public policy and environmental forces) levels on both individual and organisational levels of implementation of WLB practices (Klein, Tosi \& Cannella, 1999).

Conceptual knowledge emerging from the data suggested that conditions outside an organization and individual's sphere of life may also have large impact of influencing the realities derived from the problems that people face in meaningfully coordinating their roles at work and family levels for optimum satisfaction (Clark, 2000). Conceptual information emerged that the macro-environment factors of any national contexts are key drivers that can, to a greater or lesser extent, impact on the (in)effectiveness (Johnson, Scholes, \& Whittington, 2006) of work life balance practices and policies at individual and organizational levels. Applying the PESTEL framework, which theorizes that various environmental components, such as political, economic, social, technological, environmental and legal (PESTEL) structures of any national contexts influences people's working patterns, standard of living and lifestyles (Johnson, Scholes, \& Whittington, 2006). It also impacts on each organization within the wider industry and markets in which they operate. Therefore, in Nigeria's case, the participants were inclined to blame the country's deplorable macro-environmental component failures for lack of workable WLB practices and policies within the Nigerian organizations. For instance, one male hotel attendants working in the one of the three star hostels in Lagos pointed out that:

"Work life balance is mere theory in my workplace...this is obviously because of the political, economic and social challenges of insensitivity to working conditions at government and organizational levels. The culture of corruption is a major factor hindering our process as a nation with regards workable work-life balance practices..." Hotel Guest attendant working in a three star hotel 
There are a swathe of Nigerian publications that suggest the failing culture of corruption are derived from the love of ostentatious living and greed which is a major source of concern to all and sundry in a country with so much wealth and resources (Tiemo, 2006; Okogbule, 2007; Ampratwum, 2008; Fajana, 2008). The participants of this study attributed the worrisome impacts these failing cultures have on their quality of life and wellness to function at work and home. For instance, the Transparency International's (TI) past reports showed that Nigeria's Corruption Perceptions Index (CPI) was still at the highest and ranked four places up and "ranked above Chad, Bangladesh and Haiti showing that corruption is still a major problem" (Okpara \& Wynn 2007).

Against this backdrop, Okpara and Wynn (2007) presented facts of poor management practices amongst Nigerian managers in some organizations which stem from the larger societal that engenders lack of motivation and under-performance in most Nigerian organizations. Also, interviewees in this study expressed displeasure with the poor state of social infrastructure because of leadership insensitivity to create better social systems and conditions for her citizenry. Portable water, decent housing, constant electricity supply, good roads and functional transport systems are described to be in a poor state and a source of stress to the average Nigerian household. The country's rural and urban transport systems were ill-spoken of and equally identified as a key barrier to finding a social equilibrium in balancing their work-life roles because travel-to-work presents much societal disequilibrium. An excerpt from one of the participant's comments during the interview is that:

"Our roads is in such a deplorable state that the driving on such roads is psychological stress for me and nothing is been done by the authorities concerned to repair and mend the pot holes that are damaging most cars we use to get to work and meet family obligations..." A call-center agent working in Lagos

Within literature, it was found that the problems with travel-to-work can constitute role conflict in the lives of affected dual families. Wheatley (2012) presented in his study that time-based conflict often emanates from this situations because of the unnecessary periods spent in traffics jams which deprives dual families promptness to work or attending to family responsibilities such as picking up their children from school promptly or attending other important family engagements requiring the use of their family transport. In a similar vein, most interviewees of this study narrated similar collaborative versions relating to time-based conflict they encounter because of poor motoring facilities in Nigeria causing them unsatisfactory engagement in their family care responsibilities (Allen, 2001).

\subsection{Situations of role overload}

Another theme that emerge from data of current study was the fact that role overload was a main source of WLC for the female participants. Within literature, there are considerable large number of work-life research devoted to the perception of gender differences with particular focus on the role of men and women with regards family responsibilities and employment rights (Eby, Casper, Lockwood, Bordeaux, \& Brinley, 2005; Beutell \& Wittig-Berman, 2008).). For instance, in patriarchal cultures, the impact of role overload on women is challenging. Thus, the culture of patriarchy found in Nigeria puts women in a position where family commitments come into serious conflict with their occupational life (Aziz \& Cunningham, 2008; Mordi, Simpson, Singh, \& Okafor, 2010), while men tend to assume their primary role in the workforce as 'breadwinners' and thereby engaging less in family responsibilities. It is common knowledge that Nigerian male dominated system is essentially one of the major reasons women are subjected to serious work stress as well as family role imbalances. This has led to feelings of burnout, strain, fatigue and even chronic stress amongst female Nigerian workers who are still expected to be role models for their children and extended families.

One of our female participants amplified this position thus:

"I have three children ages 3, 8 and 12 years old to take care combined with my position as a sales manager in my motor insurance firm. My husband is also a very busy who manages our family transport business and comes back home very late every day when we are all gone to bed 
and leaves very early in the morning before anyone wakes up..." Nigerian sales manager in one of the first generation insurance companies

Role overload in this context presents an overwhelming role demands which resonates with Greenhaus and Beutell's (1985) definition of work life conflict that stems from the stringent participation in both role domains generating time and strain-based outcomes. Empathy develops when such narratives are made about some extreme challenges that women face in managing their roles as mothers and home-maker especially in Nigeria where it is found that the socialization systems and cultural orientations favor the pursuit of men above their female counterparts (Mordi, Simpson, Singh \& Okafor, 2010).

\section{Coping strategies}

Taking various adaptability beliefs into consideration, it emerged that the primary way to eliminate stressful condition is through effective deployment of coping strategies (Lazarus \& Folkman, 1984). Thus, the four established types of coping strategies in literature were examined in this study to find out ways that Nigerian workers in the service sectors cope with the nature of the stressors identified. For instance, a male participant in this study had this to say about his coping beliefs:

"It is not new that we experience perpetual conflict in our lives as Nigerians situation and my employers are of the opinion that how I balance my work and family life is my personal problem...but I have developed hardiness against the whole situation as long as I still have a job that that pays my household expenses which is always our primary concern..." Nigerian male banker Cashier

The expressions of the above male cashier working in one of the Nigerian banks resonates with the instrumental potential pathway theorized by Greenhaus and Powell (2006) in their work-family enrichment model. The narrative of the participant above stated that he still manages to derive satisfaction from the fact that his job supports his family demands and thereby makes enrichment possible for him to some extent. It can also be deduced that cognitive survival and personal hardiness are traits that have been developed as psychological and physical coping resource (Greenhaus \& Powell, 2006) by Nigerians. This coping attitude was also confirmed by other male participants of study. Hardiness is commonly taken to be a personality trait in which individuals' exercises levels of control and show enduring prowess in the face of adversity (Maddi, 2008) as found in the case of Nigeria.

This is also synonymous to the positive thinking coping theory which suggests personal decision to accommodate such stressful circumstances irrespective of the discomfort associated with it. Another emerging theme that evolved was that assistance seeking solutions of coping found to be utilized by the female participants in this study. Most of the married women in the service sectors in present study were found to outsource child care responsibilities to their parents, relatives and extended families to help out when they are at work. It also emerged that it was common practice in Nigeria to employ the services of a house helps for general household labour. This house helps, mostly young females are recruited from poor rural areas where their parents may be poor and lack basic sources of livelihood to send their young female children to primary and secondary schools but would rather send them out to serve as domestic workers in the urban cities of Nigeria. This are often low paid services and informal in nature. One of the married respondents expressed the following:

"It is unfortunate that most married women in Nigeria have to get poorly trained house helps for child care purposes...mostly village poor girls...”Female insurance broker

It was discovered that the Nigerian structure of social support is informal in nature relying on friends, families and paid house helps. However, some concerned participants in our study confirmed the challenges they experience in obtaining this unskilled helps compulsorily. It emerged that some of this social support fail to moderate the effects of WLC but rather amplifies psychological stress and role overload (Frone, Russell, \& 
Cooper, 1992; Carlson \& Perrewe, 1999). Be that as it may, it was surprising to note some divergent themes that emerged from other interviews that represented extreme views of frustration about the excruciating WLC experiences in Nigeria from four participants. One of them narrates his situation:

"I am not happy with the stress I encounter in my work which spill over psychologically into my private issue of life. This is because my salary is too small compared to my living expenses in Lagos. It seems I work so hard and live so little...I am 38 years and still single because I cannot save enough money to have a decent wedding. I do not think I can ever marry with this Nigerian situation. I am the only one who has a job in family...my other four siblings are still job seekers and I am the only one providing financially for my old parents. If I have the opportunity I would leave this country and relocate to some other neighboring countries around Nigeria which I was informed that standard of living is much more affordable...” Hotel Security and Service Guard

In this case, reactions to environmental adversity by this respondent portray chronic stress resentment. Coping methods of avoidance/resignation has often been found to be a display of one's abdication of control for the purposes of escaping from surrounding conflicts. This style of coping is sometimes said to show signs of absolute despair and drawing conclusions that nothing can change the present adversity except one finds an exit from the situation which is often exacerbated by feelings of lack of control that is necessitating prompt decisions of escape (Rotondo, Carlson, \& Kincaid, 2003).

\section{Conclusions and Study Limitations}

The entire study primarily contributes to scholarly knowledge in areas of holistic factors that can be found to influence people's perception of WLB practices and various coping strategies which are utilized to ameliorate role imbalances encountered. The Nigerian experience reveals that the macro-environmental factors have been major sources of work-family conflict. The participants employed in various service sectors in the Nigerian economy stated overwhelmingly that the nation's challenges are major causes for their role conflict. Culture of corruption, high unemployment ratios, poverty, inflation, patriarchy are some problems identified as exacerbating WLC.

In managing this conflict experiences, this study further extends knowledge by presenting how Nigerian workers adopt the various coping strategies as relief measures. Though it is established that the behavioral and cognitive coping efforts if effectively employed, moderates distressing situations, however, the Nigerian case tends to relay a salient notion that Nigerians seem to accept WLC as a way of life going by some of the narratives from participants. Personal coping strategies adopted seems to be used to suppress conflict rather than removing stressors. Interestingly, the data generated from study did not reflect anyone adopting the problem-solving approach which theorizes that individual takes specific and decisive action(s) to eliminate the stressors (Rotondo, Carlson, \& Kincaid, 2003). As earlier discussed, this highlights the hardiness culture that Nigerian workers have adopted to endure the adversities of WLC.

The practical implication of study presents an urgent need for accountable and socially responsible government and employer's sensitivity to real issues affecting workable WLB in Nigeria. This is because the well-being of a country's human resource is central to effective productivity which stimulates business growth in any sector of a nation's economy. Lack of institutionalized social support systems, disregard for a culture that encourages WLB solutions and effective enforcement of employment standards by the national government makes it possible for Nigerian employers of labor to circumvent the ideals of WLB practices and policies (Xiao $\&$ Cooke 2012). This unfortunately serves as one of the reasons for poor economic performance that has encumbered the maintenance of a sustainable and ethical business environment in Nigeria for decades.

A number of limitations also existed from the study. The study emphasized on external factors affecting WLB in the Nigerian context. This can however be justified given the overpowering conditions of the national 
Akanji, B.

challenges that participants vehemently blamed for the lack of workable WLB practices in Nigeria. The second limitation is the relatively small sample size of participants drawn from a few service sectors in Nigeria. Also, the study was concentrated in only one state in Nigeria which consists of 33 states. Nonetheless, the reason for conducting the study only in Lagos state was because of time and financial constraint. Also, the study adopted qualitative approach which makes perceptions of participants highly subjective and caution placed on generalization of findings. Future studies are suggested to reach out to other states of Nigeria while quantitative studies may be essential to confirm the validity of the subjective commentaries made by participants of existing study.

\section{References}

Adams, G. A., King, L. A., \& King, D. W. (1996). Relationships of job and family involvement, family social support and work-family conflict with job and life satisfaction. Journal of Applied Psychology, 81, 411-420. http://dx.doi.org/10.1037/0021-9010.81.4.411

Allen, T. D. (2001). Family-supportive work environments: the role of organizational perceptions. Journal of Vocational Behavior, 58, 414-435. http://dx.doi.org/10.1006/jvbe.2000.1774

Ampratwum, E. F. (2008). The fight against corruption and its implications for development in developing and transition economies. Journal of Money Laundering Control, 11(1), 76-87. http://dx.doi.org/10.1108/13685200810844514

Aziz, S., \& Cunningham, J. (2008). Workaholism, work stress, work-life imbalance: exploring gender's role. Gender in Management: An International Journal, 23(8), 553-566. http://dx.doi.org/10.1108/17542410810912681

Baral, R., \& Bhargava, S. (2010). Work-family enrichment as a mediator between organizational interventions for work-life balance and job outcomes. Journal of Managerial Psychology, 25(3), 274-300. http://dx.doi.org/10.1108/02683941011023749

Beutell, N. J., \& Wittig-Berman, U. (2008). Work-family conflict and work-family synergy for generation X, baby boomers, and matures: Generational differences, predictors, and satisfaction outcomes. Journal of Managerial Psychology, 23(5), 507-523. http://dx.doi.org/10.1108/02683940810884513

Bond, S. (2004). Organisational culture and work-life conflict in the UK. International Journal of Sociology and Social Policy, 24(12), 1-24. http://dx.doi.org/10.1108/01443330410790795

Carlson, D. S., \& Perrewe, P. L. (1999). The role of social support in the stressor-strain relationship: an examination of work-family conflict. Journal of Management, 25(4), 513-540. http://dx.doi.org/10.1177/014920639902500403

CIA. (2010). The world factbook. Retrieved November 14, 2012, from http://www.cia.gov/library/publication/the-world-factbook/geos

Clark, S. C. (2000). Work/family border theory: a new theory of work/family balance. Human Relations, 53(6), 747-770. http://dx.doi.org/10.1177/0018726700536001

Crompton, R., \& Lyonette, C. (2006). Work-life 'balance' in Europe. Acta Sociologica, 49(4), 379-93. http://dx.doi.org/10.1177/0001699306071680

Demerouti, E., Tarris, W. T., \& Bakker, A. B. (2007). Need for recovery, home-work interference and performance: Is lack of concentration the link? Journal of Vocational Behavior, 71, 204-220. http://dx.doi.org/10.1016/j.jvb.2007.06.002

Eby, L. T., Casper, W. J., \& Lockwood, A., Bordeaux, C., \& Brinley, A. (2005). Work and family research in IO/OB: content analysis and review of the literature (1980-2002). Journal of Vocational Behavior, 66, 124-197. http://dx.doi.org/10.1016/j.jvb.2003.11.003

Eikhof, D. R., Warhurst, C., \& Haunschild, A. (2007). Introduction: what work? What life? What balance? Critical reflections on the work-life balance debate. Employee Relations, 29(4), 325-333. http://dx.doi.org/10.1108/01425450710839452

Epie, C. (2009). Managing time-based conflict across life domains in Nigeria: A decision making perspective. Ife Psychological, 17, 194-216. 
An exploratory study of work-life balance in Nigeria: Employees' perspectives of coping with the role conflicts

Fajana, S. (2008). The Nigerian informal economy: Instigating decent work and pay, and national development through unionization. Employee Relations, 30(4), 372-390. http://dx.doi.org/10.1108/01425450810879358

Felstead, A., Gallie, D., \& Green, F. (2002). Work Skills in Britain, 1986-2001. London Department for Education and Skills, 27, 99-135.

Folkman, S., \& Moskowitz, J.T. (2004). Coping: Pitfalls and promise. Annual Review of Psychology, 55, 745-774. http://dx.doi.org/10.1146/annurev.psych.55.090902.141456

French, J. R. P., Jr. (1973). Person-role fit. Occupational Mental Health, 3, 15-20.

Frone, M. R., Russell, M., \& Cooper, M. L. (1992). Prevalence of work-family conflict: Are work and family boundaries asymmetrically permeable? Journal of Organizational Behavior, 13, 723-729. http://dx.doi.org/10.1002/job.4030130708

Greenhaus, J. H., \& Beutell, N. J. (1985). Sources of conflict between work and family roles. Academy of Management Review, 10, 76-88.

Greenhaus, J. H., \& Powell, G. N. (2006). When work and family are allies: a theory of work-family enrichment. Academy of Management Review, 31, 72-92. http://dx.doi.org/10.5465/AMR.2006.19379625

Greenhaus, J. H., Collins, K. M., \& Shaw, J. D. (2003). The relation between work-family and quality of life. Journal of Vocational Behavior, 63, 510-531. http://dx.doi.org/10.1016/S0001-8791(02)00042-8

Greenhaus, J. H., \& Powell, G. N. (2006). When work and family are allies: a theory of work-family enrichment. Academy of Management Review, 31, 72-92. http://dx.doi.org/10.5465/AMR.2006.19379625

Gregory, A., \& Milner, S. (2009). Work-Life Balance: A matter of Choice. Gender, Work and Organization, 16(1), 1-25. http://dx.doi.org/10.1111/j.1468-0432.2008.00429.x

Herman-Stahl, M. A., Stemmier, M., \& Petersen, A.C. (1995). Approach and avoidant coping: Implications for adolescent mental health. Journal of Youth and Adolescence, 24(6), 649-669. http://dx.doi.org/10.1007/BF01536949

Johnson, G., Scholes., K., \& Whittington, R. (2006). Exploring corporate strategy. Test and cases (7th ed.). England: Pearson Education Ltd.

Klein, K. J., Tosi, H., \& Cannella, A. A. (1999). Multilevel theory building: Benefits, barriers, and new developments. Academy of Management Review, 24, 243-248. http://dx.doi.org/10.5465/AMR.1999.1893934

Lazarus, R. S., \& Folkman, S. (1984). Stress, Appraisal and Coping. New York: Springer.

Lewis, S., \& Cooper, C. L. (1999). The work-family research agenda in changing con-texts. Journal Occupational Health Psychology, 4(4), 382-393. http://dx.doi.org/10.1037/1076-8998.4.4.382

Maddi, S. R. (2008). The courage and strategies of hardiness as helpful in growing despite major, disruptive stresses. American Psychologist, 9, 563-564. http://dx.doi.org/10.1037/0003-066X.63.6.563

Manfredi, S., \& Holliday, M. (2004). Work-life balance: An audit of staff experience at Oxford Brookes University. The Centre of Diversity Policy Research: Oxford Brookes University.

Mordi, C., Simpson, R., Singh, S., \& Okafor, C. (2010). The role of cultural values in understanding the challenges faced by female entrepreneurs in Nigeria. An International Journal: Gender in Management, 25(1), 5-21. http://dx.doi.org/10.1108/17542411011019904

Okogbule, N. S. (2007). Official corruption and the dynamics of money laundering in Nigeria. Journal of Financial Crimes, 14(1), 49-63. http://dx.doi.org/10.1108/13590790710721800

Okpara, J. O., \& Wynn, P. (2007). The impact of ethical climate on job satisfaction, and commitment in Nigeria: Implications for management development. Journal of Management Development, 27(9), 935-950. http://dx.doi.org/10.1108/02621710810901282

Okpara, J. O. (2006). Gender and relationship between perceived fairness and pay, pro-motion and job satisfaction in a sub-Saharan African economy. Women in Management Review, 21(3), 224-240. http://dx.doi.org/10.1108/09649420610657407

Robson, C. (2002). Real world research (2nd ed.). Oxford: Blackwell.

Roche, M., \& Haar, J. M. (2010). Work-family interface predicting needs satisfaction: The benefits for senior management. Journal of Social \& Behavioral Research in Business, 1(1), 12-23. 
Akanji, B.

Rotondo, D. M., \& Kincaid, J. F. (2008). Conflict, facilitation, and individual coping styles across the work and family domains. Journal of Managerial Psychology, 23(5), 484-50. http://dx.doi.org/10.1108/02683940810884504

Rotondo, D. M., Carlson, D. S., \& Kincaid, J.F. (2003). Coping with multiple dimensions of work-family conflict. Personnel Review, 3(32), 275-296. http://dx.doi.org/10.1108/00483480310467606

Sanse'au, P., \& Smith, M. (2012). Regulatory change and work-life integration in France and the UK. Personnel Review, 41(4), 470-486. http://dx.doi.org/10.1108/00483481211229384

Saunders, M., Lewis., P., \& Thornhill, A. (2007). Research methods for business students (4th ed.). London: Prentice Education Limited.

Sieber, S. D. (1974). Toward a theory of role accumulation. American sociological review, 39(4), 567-578. http://dx.doi.org/10.2307/2094422

Tiemo, P. A. (2006). Obasanjo Presidential Library: To be or not to be? The bottom line. Managing Library Finances, 19(1), 31-34. http://dx.doi.org/10.1108/08880450610643043

Valcour, M. (2007). Work-based resources as moderators of the relationship between work hours and satisfaction with work-family balance. Journal of Applied Psychology, 92(6), 1512-1523. http://dx.doi.org/10.1037/0021-9010.92.6.1512

Wheatley, D. (2012). Work-life balance, travel-to-work, and the dual career household. Personnel Review, 41(6), 1-39. http://dx.doi.org/10.1108/00483481211263764

Xiao, Y., \& Cooke, F. L. (2012). Work-life balance in China? Social policy, employer strategy and individual coping mechanisms. Asia Pacific Journal of Human Resources, 50, 6-22. 